\title{
Intermittent Flow Regimes in a Transonic Fan Airfoil Cascade
}

\author{
J. Lepicovsky \\ QSS Group, Inc., NASA GRC, Cleveland, OH 44135
}

\author{
E. R. McFarland and R. V. Chima \\ NASA Glenn Research Center, Cleveland, $\mathrm{OH} 44135$
}

\author{
V. R. Capece* and J. Hayden \\ University of Kentucky, Paducah, KY 42002
}

Taylor \& Francis

Taylor \& Francis Group

\begin{abstract}
A study was conducted in the NASA Glenn Research Center (NASA-GRC) linear cascade on the intermittent flow on the suction surface of an airfoil section from the tip region of a modern low aspect ratio fan blade. Experimental results revealed that, at a large incidence angle, a range of transonic inlet Mach numbers exist where the leading-edge shockwave pattern was unstable. Flush-mounted, high-frequency response pressure transducers indicated large local jumps in the pressure in the leading edge area, which generates large intermittent loading on the blade leading edge. These measurements suggest that for an inlet Mach number between 0.9 and 1.0, the flow is bi-stable, randomly switching between subsonic and supersonic flows. Hence, it appears that the change in overall flow conditions in the transonic region is based on the rate of switching between two stable flow states rather than on the continuous increase of the flow velocity. To date, this flow behavior has only been observed in a linear transonic cascade. Further research is necessary to confirm this phenomenon occurs in actual transonic fans and is not the by-product of an endwall restricted linear cascade.
\end{abstract}

Keywords Transonic flow, Shock waves, Supersonic flow, Unsteady flow, Linear compressor cascade, Precompression blades

\section{INTRODUCTION}

Modern turbofan engines employ a highly loaded, low-aspect ratio fan stage with transonic or low-supersonic velocities in the blade-tip region. The blade-tip airfoil sections are designed for precompression, with a concave suction surface just downstream

Received 26 June 2003; in final form 10 September 2003.

*Corresponding author. Tel.: (270)534-3123, Fax: (270)534-6292. E-mail: vcapece@engr.uky.edu of the leading edge (negative camber), and with very little overall camber. These airfoil sections have a sharp leading edge and are prone to flow separation at off-design conditions. Due to extreme flight envelope requirements, military engines operate at part speed where the incidence angle is large and the blade-tip relative Mach number is high subsonic or transonic. These operating conditions make the fan blades susceptible to stall flutter. Blade flutter and associated high cycle fatigue problems are very detrimental to engine health and must be avoided. However, the origins of stall flutter are still not fully understood. Therefore, there has been a great deal of interest in fan blade stall flutter research in recent years.

The NASA-GRC linear oscillating cascade facility is being used in an experimental program to further our understanding of stall flutter. While conducting experiments at transonic Mach numbers, a flow behavior was found that may contribute to the onset of blade flutter at transonic relative Mach numbers. This phenomenon manifested itself as an instability of the leadingedge shock-wave pattern, flow intermittency, at transonic inlet flows.

Until now these flow visualization results have not been supported by direct measurements of local unsteady static pressures on the airfoil suction side at the blade leading edge. So far, the transonic airfoils, with very thin and sharp leading edges, have been instrumented with conventional static taps that are not capable of recording rapid pressure changes. Conventional static taps effectively average the fluctuating pressure, with the measured average value depending, to a large extent, on the particular configuration of the measurement system. Such data cannot reveal any intermittency of a transonic cascade flow. To substantiate the intermittent flow behavior in a transonic cascade, blades instrumented with miniature pressure transducers were used to measure the unsteady pressures on the airfoil suction side just downstream of the leading edge. 


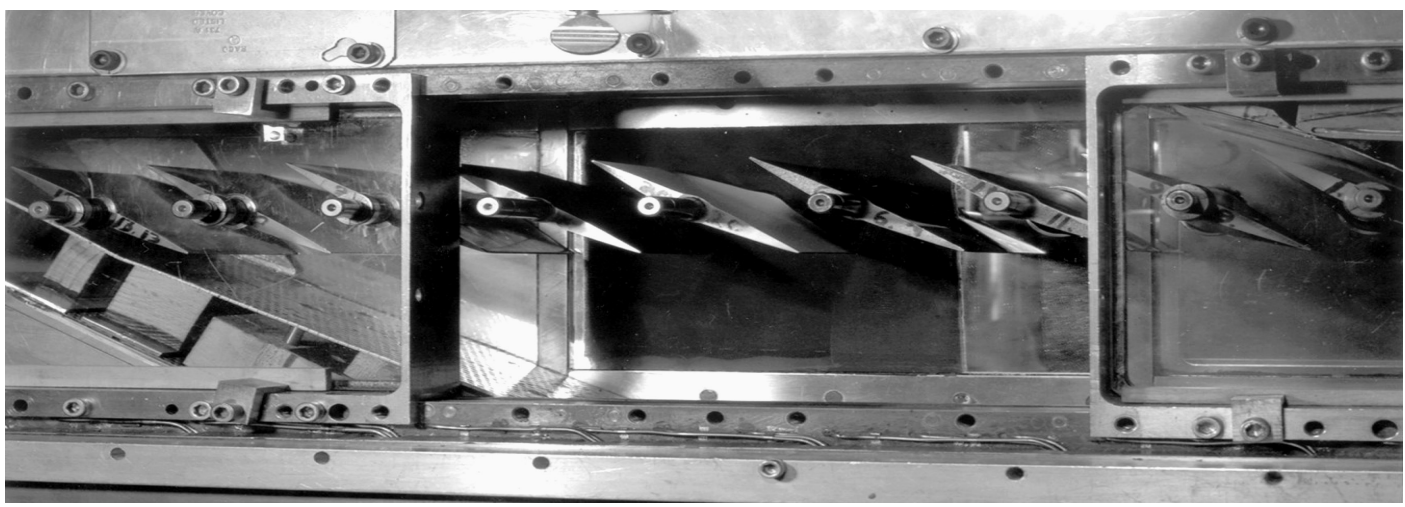

FIGURE 1

Test section of the NASA Transonic Flutter Cascade.

\section{TEST FACILITY UPGRADE}

NASA-GRC operates a unique test facility dedicated to transonic cascade flutter research. The facility, NASA Transonic Flutter Cascade (TFC), has been described in detail in Buffum et al. (1996), Boldman and Buggele (1978), and Shaw et al. (1986). The facility is a linear cascade of nine blades. A view of the cascade test section is seen in Figure 1. The airfoil and cascade parameters are given in Figure 2 and Table I (Buffum et al., 1996; Lepicovsky et al., 2000b). Blades in the cascade can be oscillated to simulate blade flutter motion. For the present study, however, the blades were fixed and no forced oscillations of the blades took place. The blades were firmly clamped and there is no freedom for torsional movement. The uncertainty in the blade setting angle is $0.08^{\circ}$.

The NASA-TFC was recently modified and upgraded to improve the flow periodicity in the cascade. This effort was undertaken because research of flutter phenomena in a linear cascade requires very good overall flow uniformity and, in particular, a high degree of flow periodicity over many blades. First, a numerical study was carried out to improve the periodicity of the tunnel and to better quantify the inlet and exit conditions needed for accurate Computational Fluid Dynamics (CFD) predictions (Chima et al., 2000; Lepicovsky et al., 2001). Several configurations of the tunnel endwalls were investigated in order to improve the periodicity of the cascade.
The configurations were designed using CFD analyses of the complete tunnel and analyses of isolated blades (Chima et al., 2000).

The PCSTAGE turbomachinery analysis panel code, developed by McFarland $(1993,1994)$, was used to model the complete tunnel configuration, including all nine blades and the endwalls. The endwalls were modeled as a tenth body with one surface shaped like the left wall of the tunnel and the other surface shaped like the right wall. Calculations were made at $M a=0.5$ to minimize compressibility effects. Figure 3 shows Mach number contours calculated for this configuration using PCSTAGE. The contours show very uniform flow ahead of the cascade.

The quasi-three-dimensional (Q-3-D) turbomachinery analysis code, RVCQ3D, developed by Chima $(1987,1995)$ was used to analyze the blades. The code solves the thin-layer NavierStokes equations in finite-difference form. To improve the periodicity of the cascade, the endwall turning was adjusted to match the turning of a perfectly periodic cascade modeled by RVCQ3D. Figure 4 shows blade surface pressure distributions measured on blade B5 (see Figure 5) at inlet Mach numbers of $0.5,0.8$, and 1.0. Pressure distributions computed with RVCQ3D are also shown. Computed static pressure ratios across the cascade matched measured values closely, confirming that the endwall interference had been minimized.

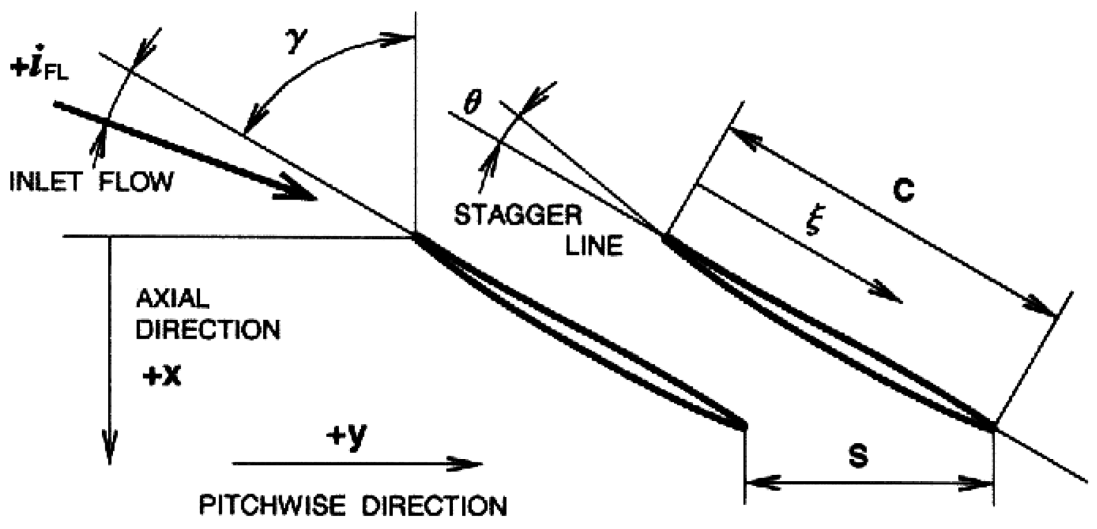

FIGURE 2

Airfoil and cascade coordinate system. 
TABLE 1

Airfoil and Cascade Parameters.

Blade chord, $\mathrm{C}$

$89.2 \mathrm{~mm}$

Leading edge camber angle, $\theta$

$-9.5 \mathrm{dg}$

Maximum thickness, $t_{\text {max }}$

$0.048 \mathrm{C}$

Location of maximum thickness, $\xi_{\max }$

$0.625 \mathrm{C}$

Stagger angle, $\gamma$

$60.0 \mathrm{dg}$

Number of blades in the cascade

9

Blade pitch, $\mathrm{S}$

$58.4 \mathrm{~mm}$

1.53

$0.5 \mathrm{C}$

$95.9 \mathrm{~mm}$

\section{BLADE LOADING PERIODICITY}

Blade steady loading periodicity was verified by measuring surface pressures for all nine blade positions by marching the instrumented blades with conventional static pressure taps through the cascade. The tunnel operating conditions were repeatable to within $1 \%$ of the inlet Mach number for each blade position. To visualize the differences in loading diagrams between blades, the center blade (B5) was taken as a reference and compared to the other blades. The pressure distribution on blade B5 is shown in Figure 4 for $M a=0.8$. The differences between this reference pressure distribution and the pressure distributions on the other blades were computed and are plotted in Figure 5. The sketch at the top of the figure identifies individual blades with color-coded numbers. The two figures show the measured differences in pressure coefficients for the blade suction side, with the left and right sides of the cascade shown in the left and right plots, respectively. Blade B5 is represented by a straight black broken line. The deviation curves for the remaining blades are color coded in accordance with the blade numbers in the sketch. For a perfectly periodic flow, all deviation curves would collapse to the broken straight line of blade B5. Positive values of deviation indicate that a particular blade has a higher pressure coefficient than blade B5 at the same chordwise station. Negative values indicate a lower value than blade B5. All pressures in the cascade were measured using absolute pressure transducers with a range of $100 \mathrm{kPa}$ and accuracy better than $\pm 0.4 \%$. This

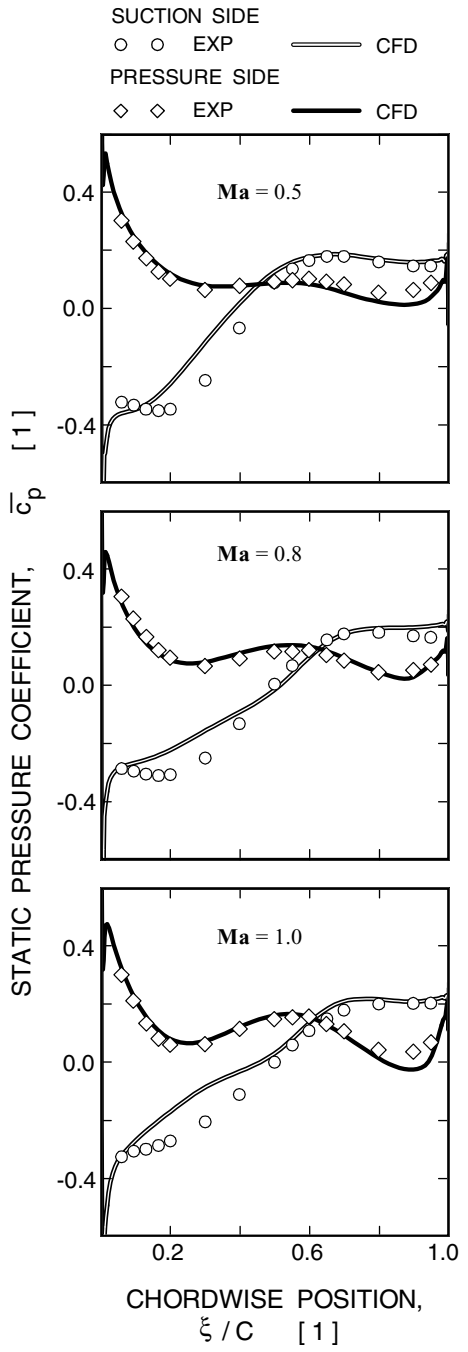

FIGURE 4

Computed and measured blade loading diagrams for middle blade (B5).

indicates an accuracy of \pm 0.02 for the value of pressure coefficient. Therefore, deviations of pressure coefficient less than \pm 0.04 are considered to be insignificant. Blades B2 through B5 in the left half of the cascade show excellent agreement of

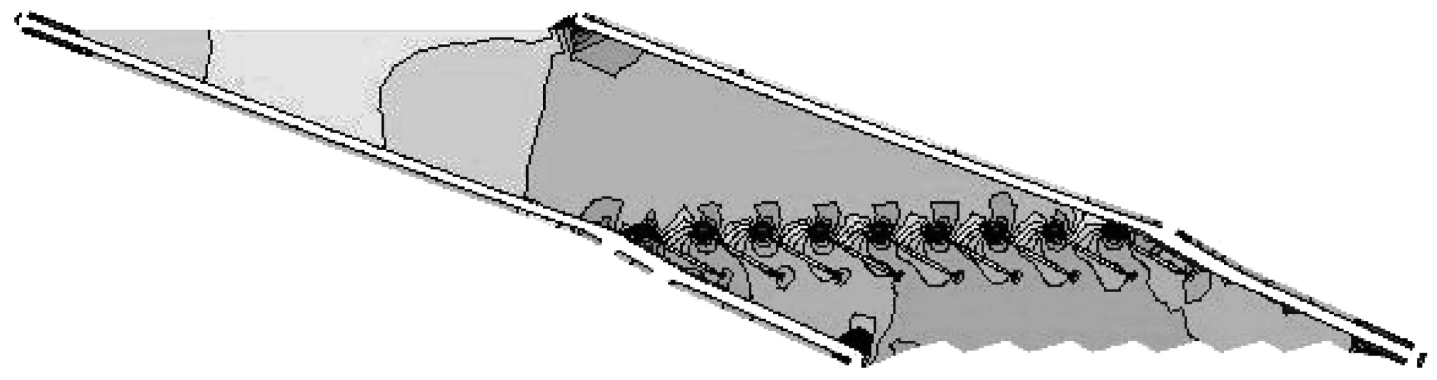

FIGURE 3

Mach number contours computed with PCSTAGE for final cascade configuration. 


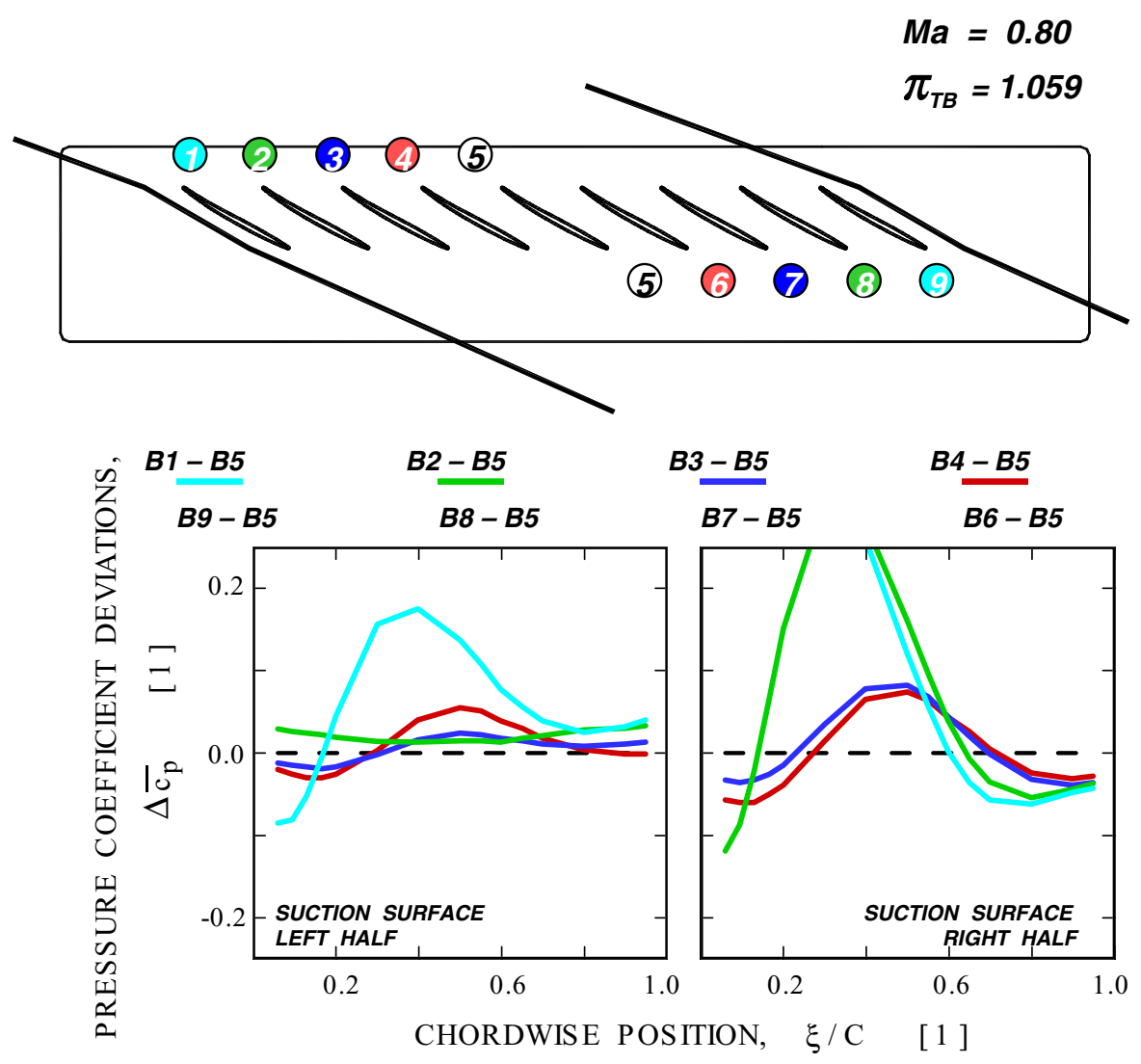

FIGURE 5

Measured blade loading periodicity.

pressure distributions on the suction surface. Blades B5 through B7 in the right half show acceptable agreement in their suction side pressure distributions. Overall, the cascade shows excellent periodicity over six blades, numbers B2 through B7. The high degree of blade-loading periodicity boosted the confidence in the cascade data and its extrapolation to the transonic fan condition.

\section{UNSTEADY FLOW IN TRANSONIC CASCADES}

Available pressure data from a transonic airfoil, measured on the suction side in the leading edge region using conventional static taps, exhibit a smooth and continuous drop with increasing inlet Mach number. Such data indicates that the local flow velocity continuously increases from subsonic to low supersonic values. However, this contradicts the observations of unsteady and intermittent behavior of the flow shock pattern for transonic inlet flow conditions.

The sequence of photographs in Figure 6 illustrates shock pattern development (Lepicovsky et al., 2000a). For the subsonic Mach numbers of 0.6 and 0.9 (Figures 6a and 6b) there are no shocks present in the flow. The first appearance of shock waves in the flow occurs for the inlet flow Mach number of 1.01 (Figure 6c). As seen here, the shock structure is not periodic; each blade shows a different shock pattern. Blades B4 and B5 generate simple normal shocks, whereas on blades B6 and B7 the shock structure appears to consist of an oblique shock followed by a bow shock. The location of the bow shock, particularly on blades B6 and B7, varies significantly. Direct observation of the shock structure for this inlet Mach number revealed that the shock structure was highly unstable and varied rapidly. Once the inlet Mach number was raised to 1.05 , the shock structure noticeably stabilized and exhibited the pattern shown in Figure 6d. The shock pattern appears to be periodic with a period equal to two blade pitches. Even blades (B4 and B6) generate normal shocks at $40 \%$ of the blade chord, whereas odd blades (B5 and B7) clearly show a horizontally located oblique (lip) shock attached to the blade leading edge and a normal shock (bow) at $25 \%$ of the blade chord. For the inlet Mach numbers of 1.12 and higher (Figures 6e-6g) the shock structure is highly periodic with the period of one blade pitch.

Surface flow visualization using an oil-paint mixture clearly shows that there are different flow patterns for subsonic and supersonic inlet Mach numbers. Four surface flow patterns are shown in Figure 7 for inlet Mach numbers of 0.5, 0.8, 1.0, and 1.18. There is a large separated flow region on the blade suction surface just past the leading edge exhibiting a complex threedimensional flow structure for the subsonic inlet Mach numbers. For the supersonic inlet flow, however, the flow past the leading 

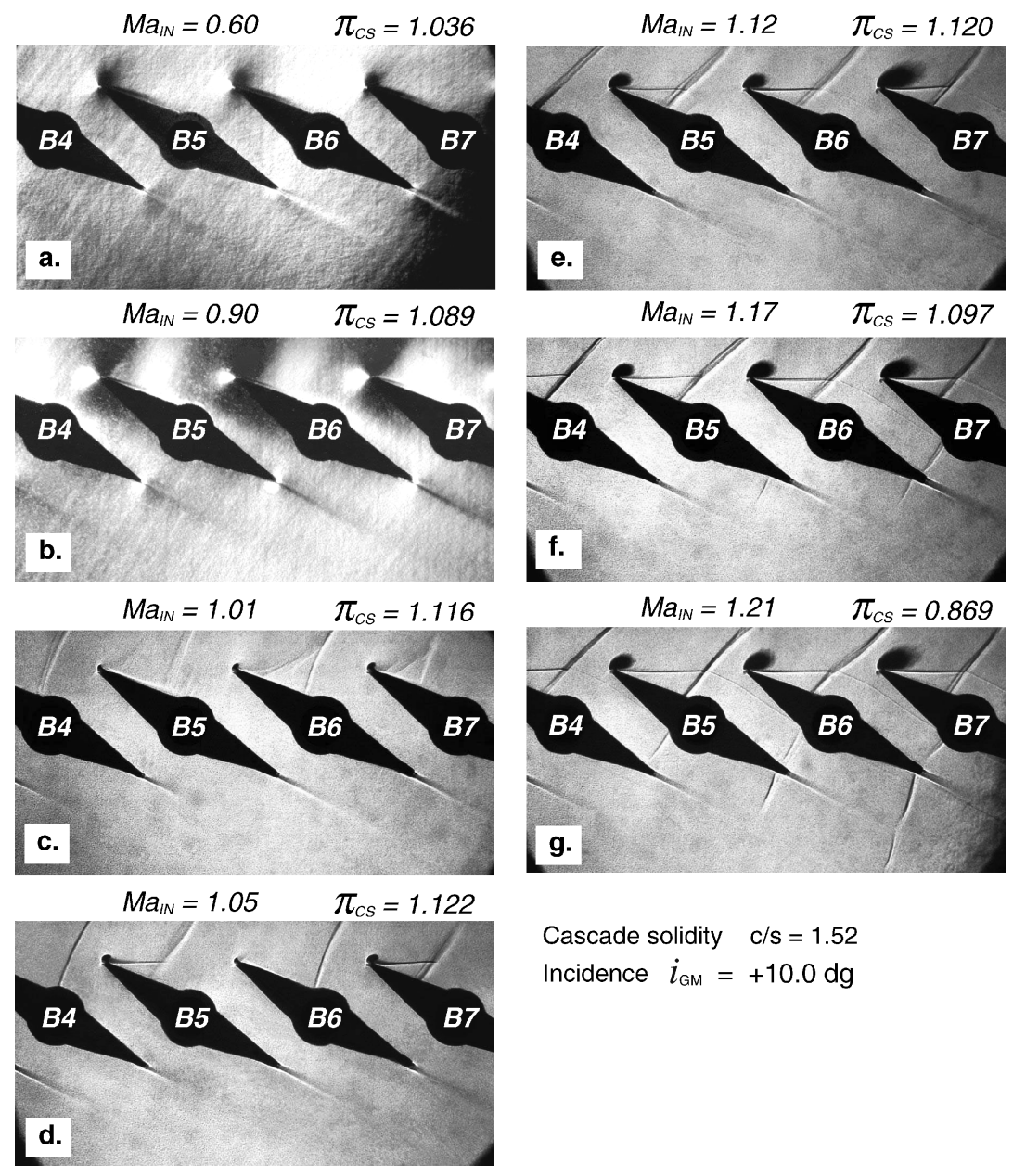

Incidence $i_{\mathrm{GM}}=+10.0 \mathrm{dg}$

FIGURE 6

Shadowgraph visualization of shock wave pattern.

edge is fully attached to the blade for a considerable length. This abrupt change of surface flow patterns is also not indicative of a smooth velocity increase through the transonic flow region.

\section{UNSTEADY SURFACE PRESSURES}

Three blades with instrumentation on the suction surface were used in this study. One blade had 15 conventional static pressure taps along the midspan line, and 2 blades had 15 miniature highfrequency pressure transducers (Kulite XCQ-062-15A) with a nominal range of 0 to $100 \mathrm{kPa}$ absolute. Details of the blade instrumentation and data acquisition procedures can be found in Lepicovsky et al. (2002). Only data from port 1, located at the blade midspan $6.0 \%$ of the blade chord downstream of the blade leading edge, are presented here. The instrumented blades were marched through the cascade to record pressures for various blade positions in the cascade. Data for blade positions 3, 4, 6, and 7 will be presented.

First, the recorded pressure time histories from the unsteady pressure transducer were averaged and compared with conven- tional static pressure tap data for each of the investigated positions. Figure 8 presents comparisons of static tap data and averaged unsteady data in the form of pressure coefficient versus inlet Mach number. As seen here, there is relatively good agreement between these sets of data. The differences are not larger than those presented previously in Figure 5. Unsteady measurements allow quantification of pressure fluctuations (root-mean-square values) as a function of the inlet Mach number. This is shown in Figures 9a and 9b, where comparison of absolute pressure levels is plotted in upper diagrams and levels of pressure fluctuations are plotted in lower diagrams. There are no noticeable differences among investigated blades. The fluctuation levels are shown in pressure units. In relative terms, the level of pressure fluctuation is about $1 \%$ of the average pressure value up to the inlet Mach number of 0.5 , but then increases to a level of 18 to $20 \%$ for the inlet Mach number equal to 1.0. Then the fluctuation level abruptly drops to $2 \%$ and stays at this level up to the maximum Mach number tested $(M a=1.1)$.

A series of time resolved pressure signals is presented in Figures 10a-10c. The series is for a range of inlet Mach 


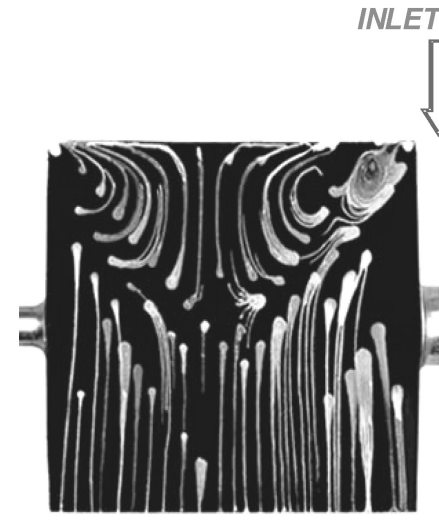

$M a=0.50$

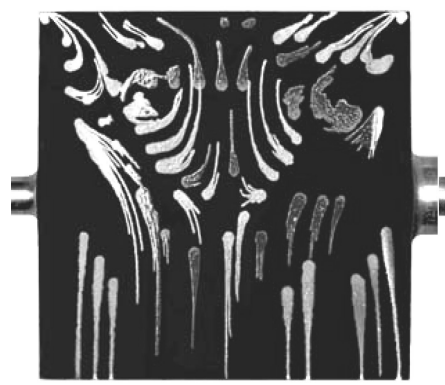

$M a=0.80$<smiles>CCCCC=C(C)C</smiles>

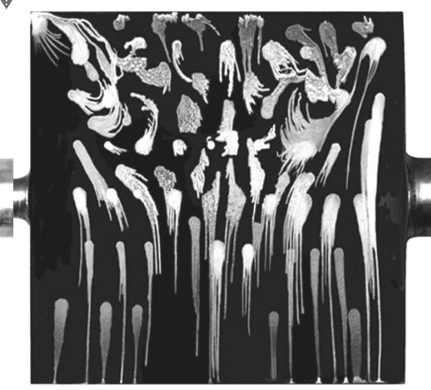

$M a=1.00$

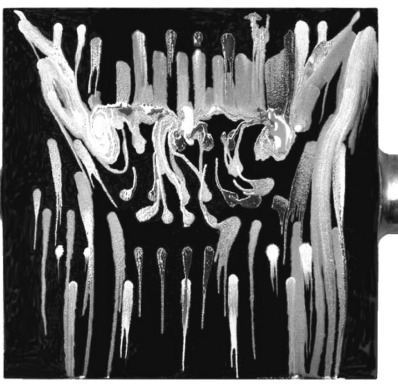

$M a=1.18$

FIGURE 7

Visualized surface flow patterns.

$\Longrightarrow$ STEADY DATA

$\longrightarrow$ UNSTEADY DATA

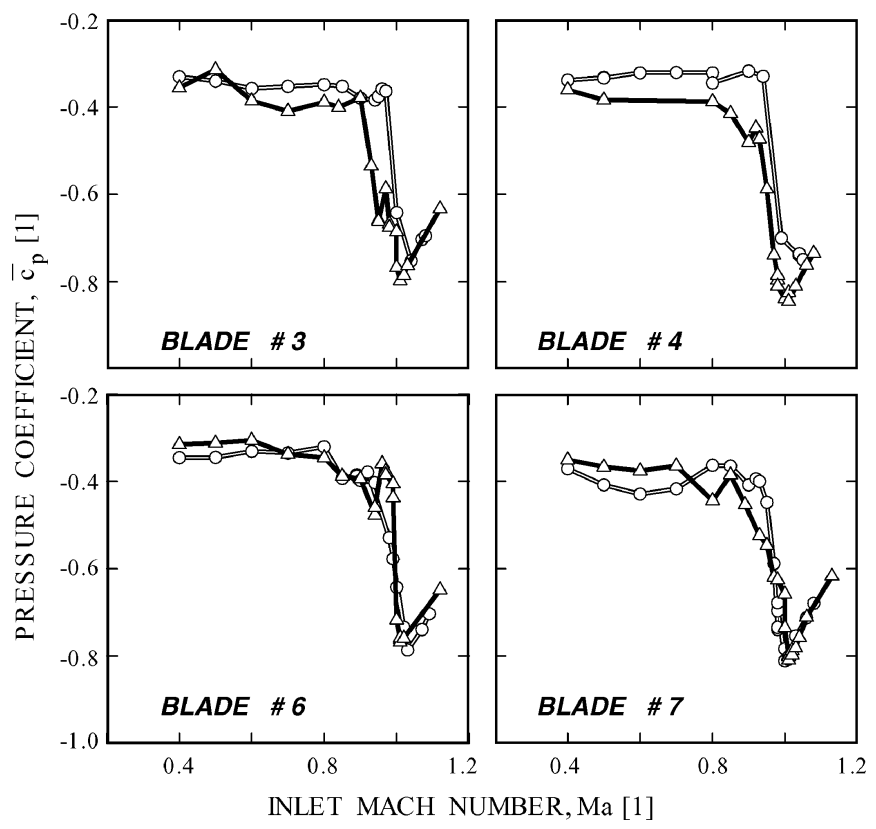

FIGURE 8

Pressure coefficient as a function of inlet Mach number.

$\Longrightarrow$ STEADY DATA

$\longrightarrow$ UNSTEADY DATA
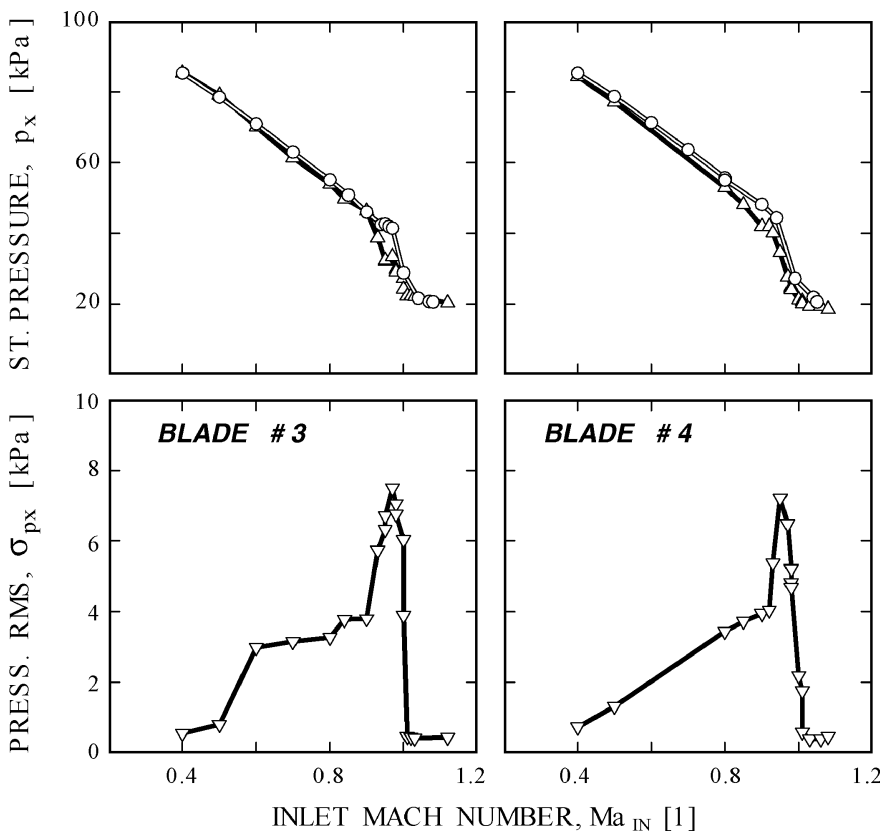

FIGURE 9a

Local surface pressure and pressure unsteadiness as a function of Mach number.

$\Longrightarrow$ STEADY DATA

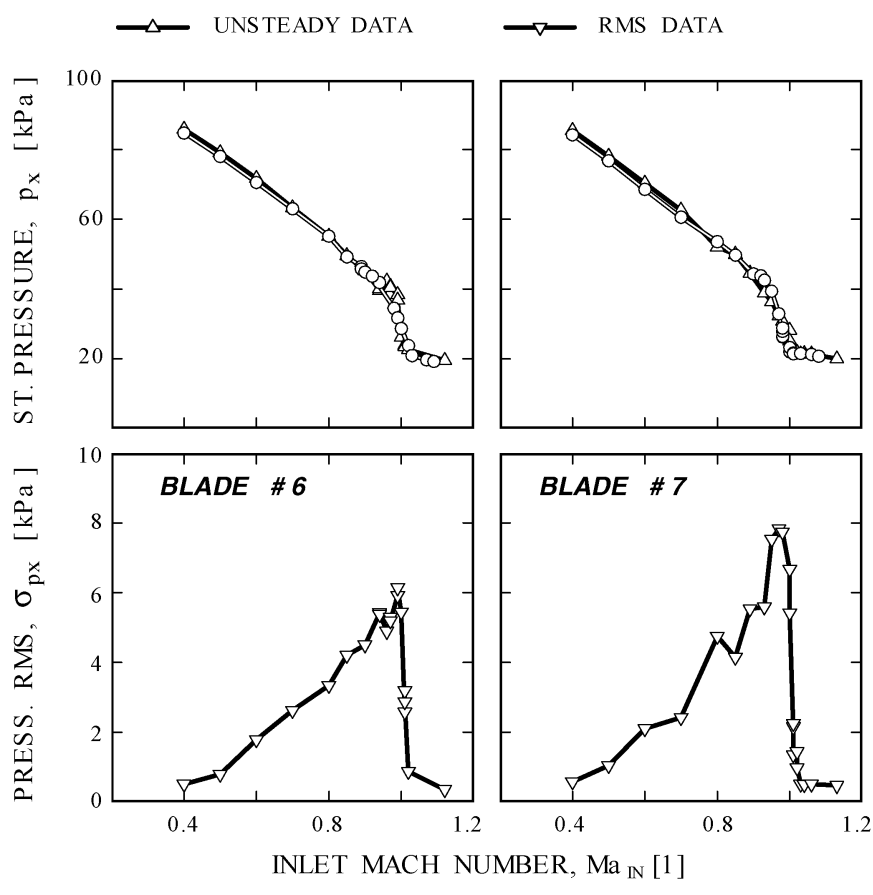

FIGURE 9b

Local surface pressure and pressure unsteadiness as a function of Mach number. 

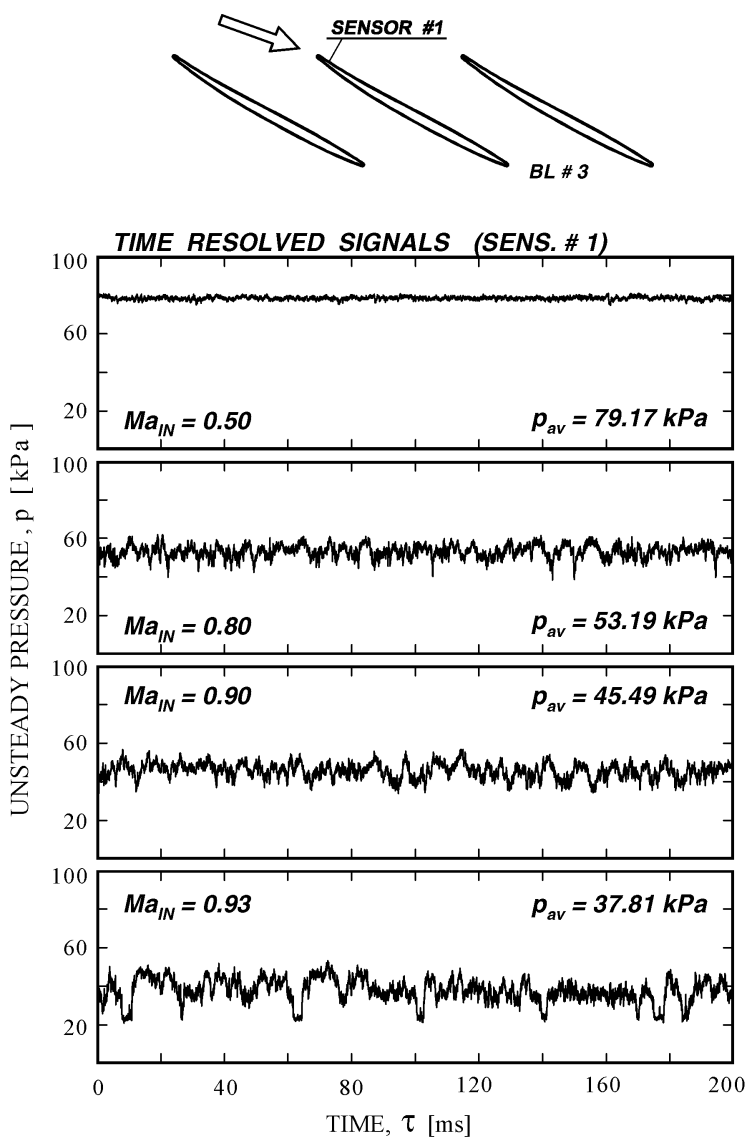

FIGURE 10a

Time resolved pressure signal at port 1 for different inlet Mach numbers.

numbers from 0.5 to 1.02 . As seen here, unsteadiness of the pressure signals rapidly increases with increasing inlet Mach number up to $M a=0.93$. At this inlet Mach number a new phenomenon takes place. Starting at this Mach number there are momentary pressure level drops to a level for which the flow velocity jumps to a supersonic value. It should be emphasized here that the changes are not smooth and gradual transitions, but sudden pressure jumps. These bursts of supersonic velocity are at first very short (a few milliseconds) and infrequent. However, with increasing inlet Mach number, the duration and number of appearances of supersonic flow velocities increases dramatically. For an inlet Mach number of about 0.95 to 0.97 , the local flow velocity at the blade leading edge is supersonic half of the time. However, it appears that the velocity is still switching randomly. As the Mach number increases further, the regions of supersonic flow velocity rapidly lengthen with very sporadic instances of subsonic velocity pockets. Finally, for inlet Mach numbers of 1.01 the pressure level has settled at a value of about $20 \mathrm{kPa}$, which corresponds to established continuous supersonic flow.
TIME RESOLVED SIGNALS (SENS. \# 1)

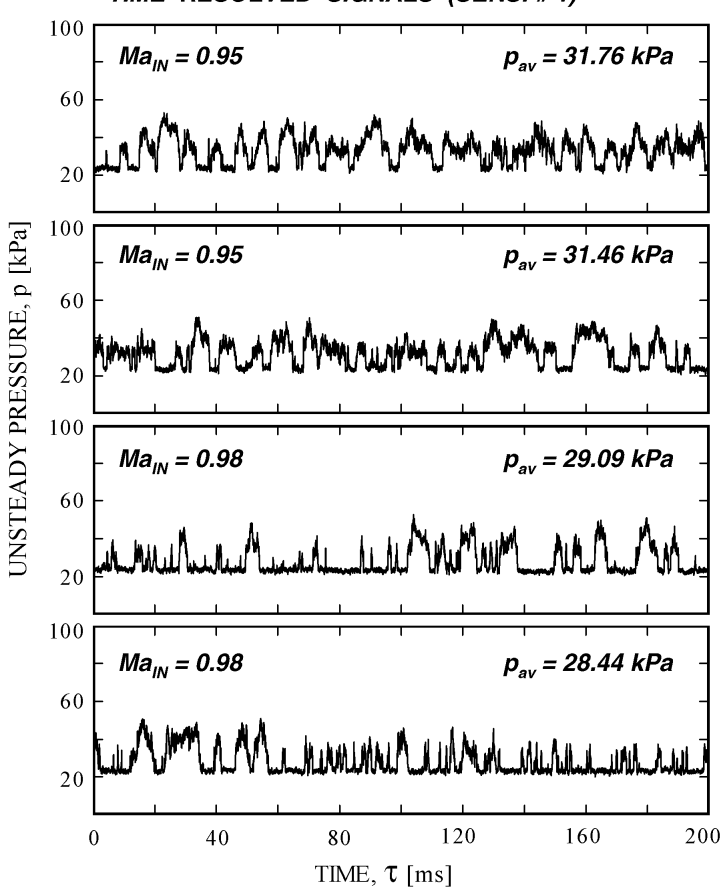

FIGURE 10b

Time resolved pressure signal at port 1 for different inlet Mach numbers.

TIME RESOLVED SIGNALS (SENS. \# 1)

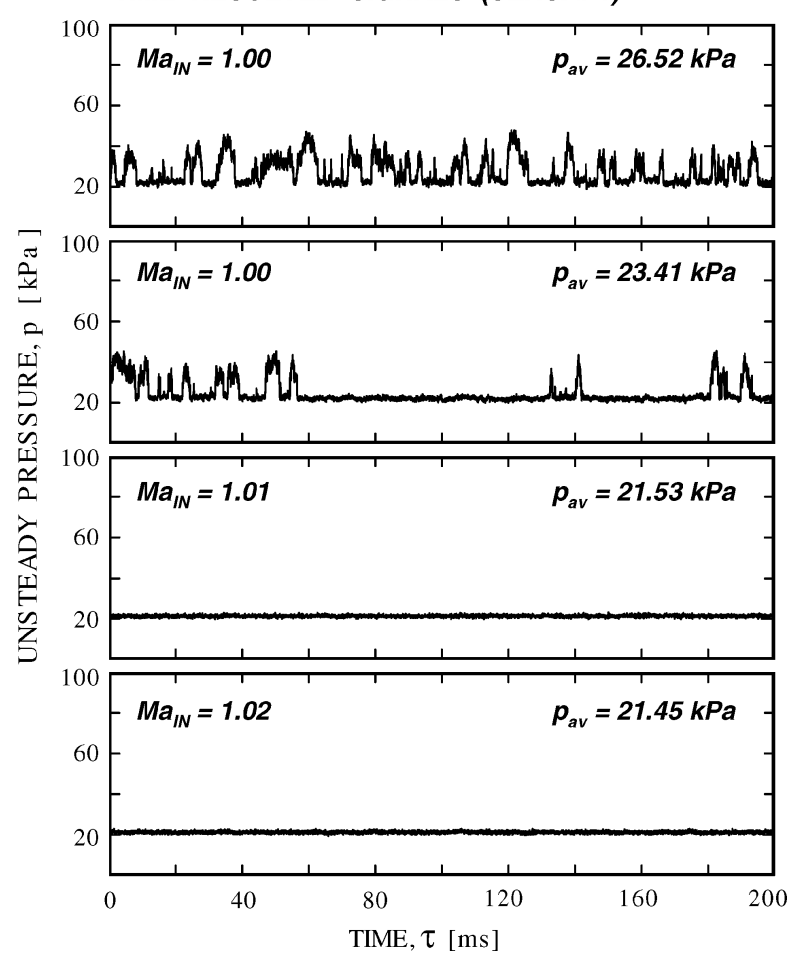

FIGURE 10c

Time resolved pressure signal at port 1 for different inlet Mach numbers. 

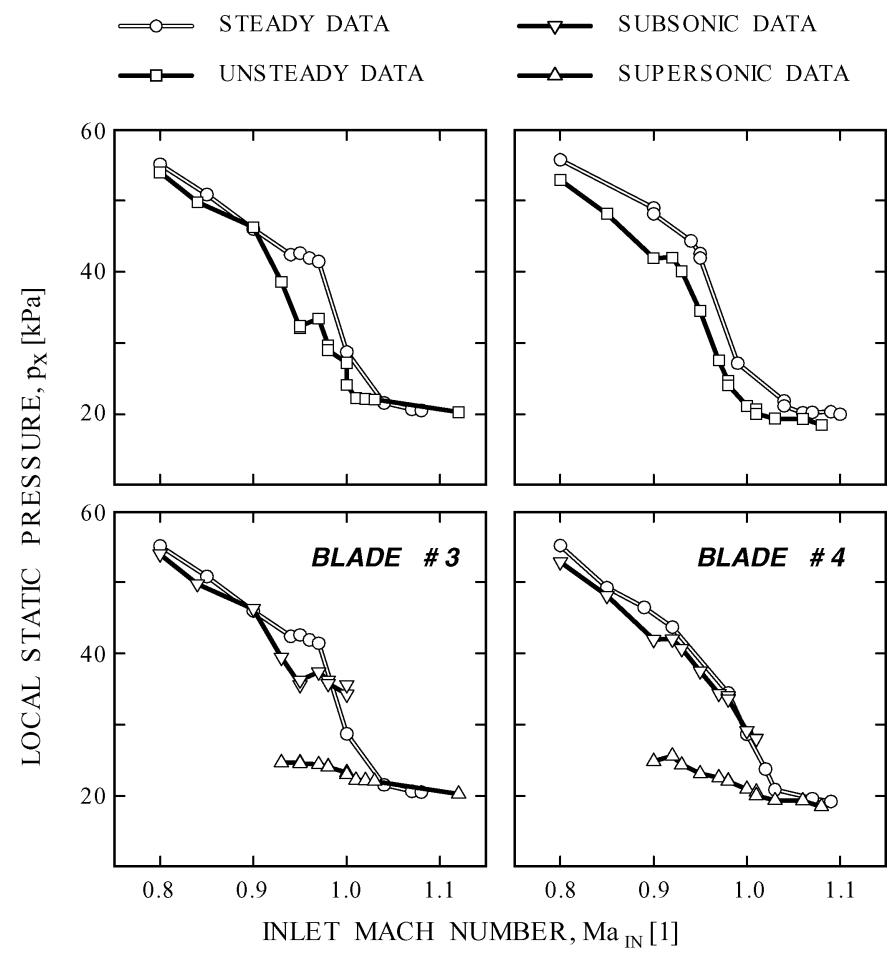

FIGURE 11a

Pressure distributions for subsonic and supersonic intermittent flows.

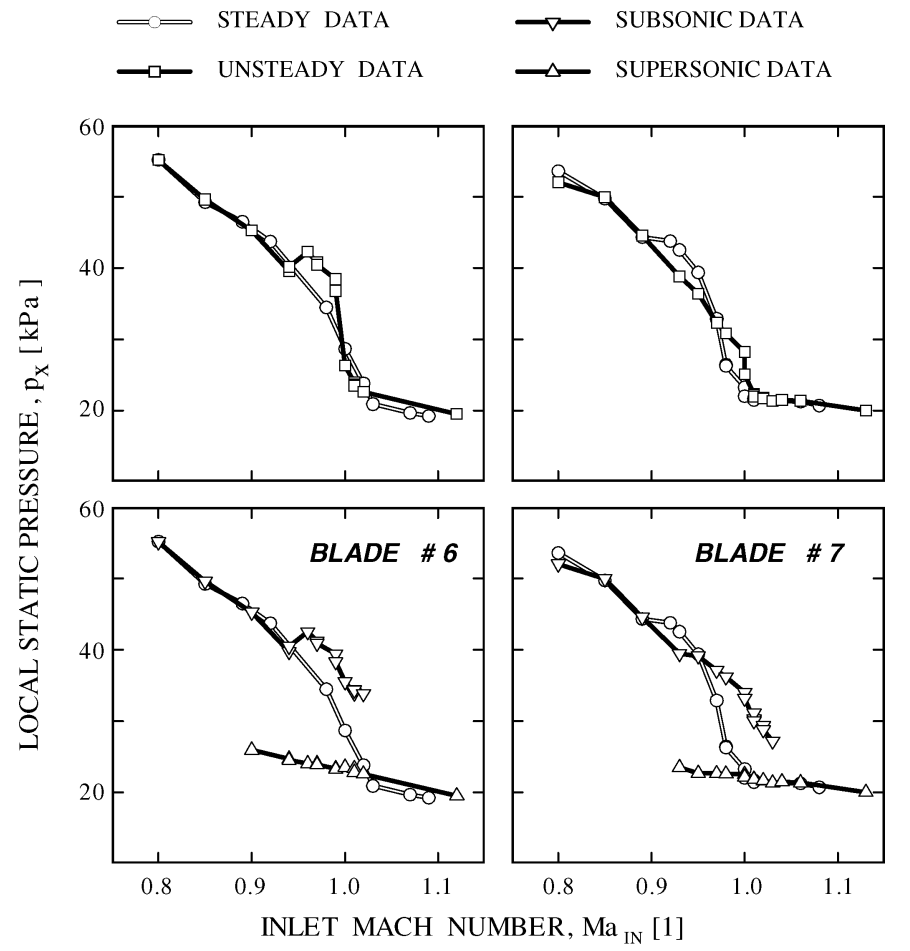

FIGURE 11b

Pressure distributions for subsonic and supersonic intermittent flows.

\section{FLOW INTERMITTENCE}

The jumps in the local pressure level in the blade leading edge region are about 20 to $25 \mathrm{kPa}$ for the Mach number range from 0.9 to 1.0. It appears that the flow just past the leading edge is bi-stable, randomly switching between the subsonic and supersonic flows. To reveal the bi-stable character of the flow, a threshold was set for the midlevel of pressure drops (27 kPa in this particular case), and the measured pressure was averaged for segments of pressure level above this threshold and segments below the threshold. The results are presented in Figures $11 \mathrm{a}$ and $11 \mathrm{~b}$. The upper diagrams show comparison of static tap data and overall averages of unsteady data. The lower diagrams show three distributions: static tap data, averaged unsteady data for subsonic flow, and averaged data for supersonic flow. As seen here, a smooth pressure drop in this region measured by the conventional static taps is an artifact of the averaging process of this pressure measuring method. It appears that in reality the change in overall flow conditions in the transonic flow region is based on the rate of switching between two stable flow states rather than on the continuous increase of the flow velocity.

A flow intermittence function for any inlet Mach number that indicates flow stability in the region of bi-stable switching between high subsonic and low supersonic local velocities can be defined. It can be viewed as a time fraction of flow being at supersonic velocities in the bi-stable region. It has a value of 0 for flow that is fully subsonic and a value of $1(100 \%)$ for flow that is fully supersonic. Figures $12 \mathrm{a}$ and $12 \mathrm{~b}$ presents this function for the investigated four blades. The lower diagrams in the same
BLADE \# 3

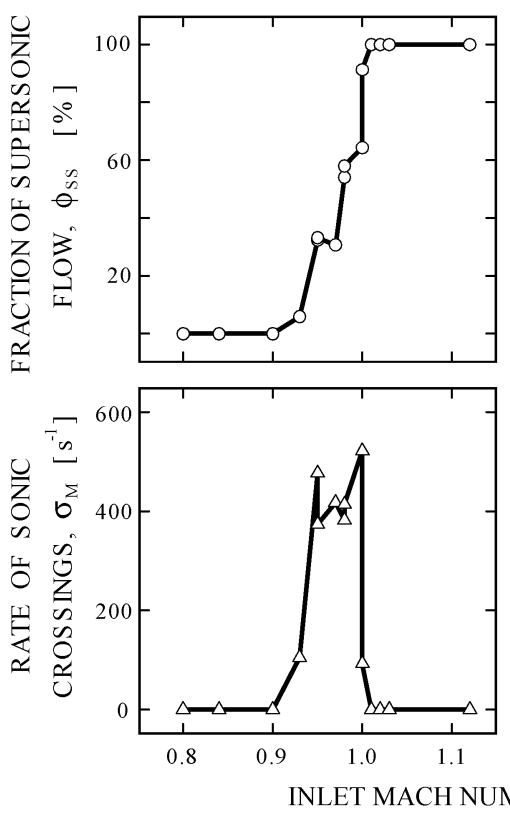

BLADE \# 4

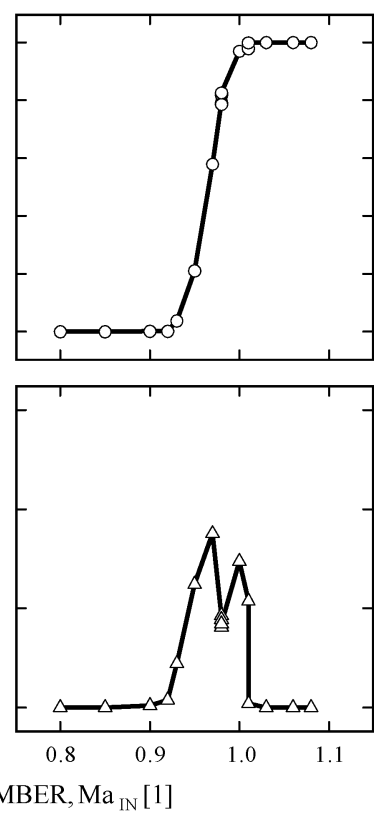

FIGURE 12a

Intermittency parameters for blades B3 and B4. 


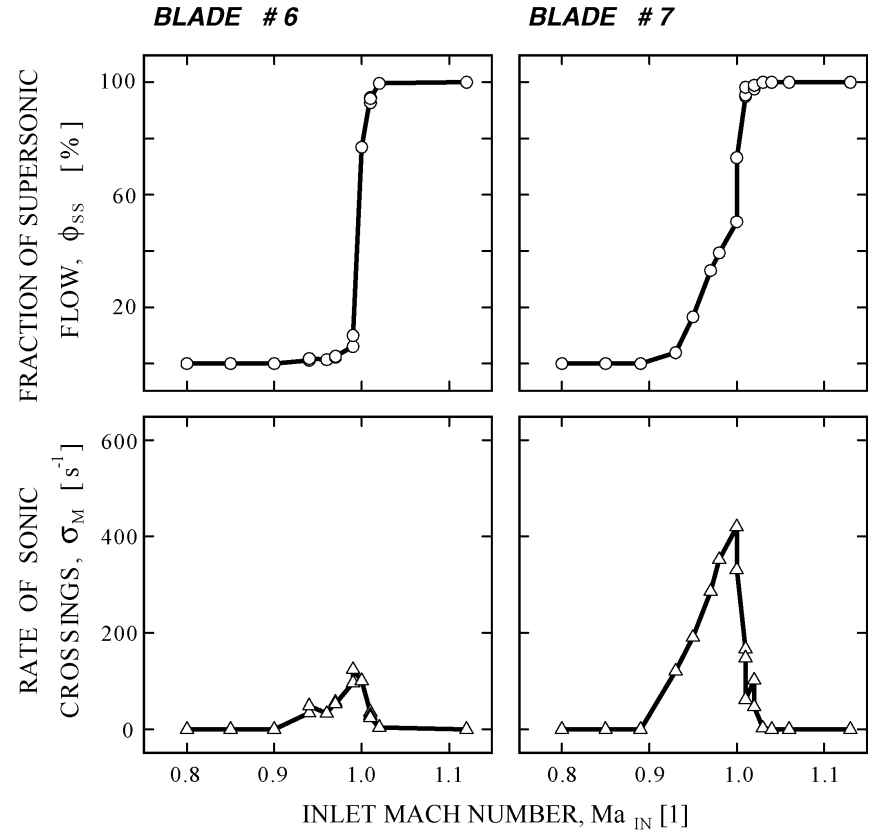

FIGURE 12b

Intermittency parameters for blades B6 and B7.

figure show the rate of sonic crossings per second for the bistable region. The rate of sonic crossings is actually the rate of pressure jumps. Therefore, it is the rate of unsteadiness in blade loading (blade forcing function). If this rate is close to any of the blade natural frequencies, blade oscillations will be excited. It appears from the data presented that the inner blades exhibit a lower rate of zero crossings than the blades closer to the cascade endwalls. In other words, it depends on the blade position in the cascade. This may indicate that the phenomenon of flow intermittency is somehow associated with the linear cascade flow conditions. At present, this observation is purely speculative, based on this single data set, and needs to be confirmed with data from other facilities.

\section{CONCLUSION}

The phenomenon of flow intermittency in a transonic cascade for high-speed subsonic inlet Mach numbers with high incidence has not been reported previously in the open literature. Flow appears to be bi-stable for these conditions. Pressure jumping between two levels in the transonic region generates large intermittent loading on the blade leading edge region and can lead to the onset of blade vibration. To date, this flow behavior has only been observed in a linear transonic cascade. Based on these observations the following question arises: Can this new model of the flow physics, devised from linear transonic fan blade cascade data, be applied to an annular transonic cascade or even to an actual transonic fan? No data from annular cascades or transonic fans has been reported to confirm or disprove it. In other words, does this phenomenon occur in actual transonic fans or is this only a by-product of an endwall restricted linear cascade? At present, this question cannot be answered decisively. In either case, this finding will affect future research on transonic blading. If the flow intermittence observed is a general phenomenon, then it will impact computational methods for transonic fans, in particular, blade life prediction codes that are not yet fully reliable. If this phenomenon is restricted only to linear transonic cascades, then any linear cascade data for high subsonic and sonic inlet Mach numbers must be treated with the utmost caution. Consequently, future research on transonic blading should be conducted in annular cascades.

\section{ACKNOWLEDGMENTS}

This work was sponsored by the NASA Glenn Research Center under the Smart Efficient Components program managed by Mr. R.D. Corrigan. The authors would like to thank Mrs. L. Shaw, chief of the GRC Compressor Branch, for her continuous support.

\section{NOMENCLATURE}

C [mm] airfoil chord

$\bar{C}_{p} \quad[1]$ steady surface pressure coefficient, $\left(P(\xi)-\bar{P}_{1}\right) /$ $\left(0.5 \bar{\rho}_{1} \bar{V}_{1}^{2}\right)$

$h \quad[\mathrm{~mm}]$ blade height

$i_{F L} \quad[\mathrm{dg}]$ flow incidence angle

$i_{G M} \quad[\mathrm{dg}]$ geometric incidence angle

Ma [1] Mach number

$p_{\mathrm{av}} \quad[\mathrm{kPa}]$ average surface static pressure

$p_{x} \quad[\mathrm{kPa}]$ surface static pressure

$S \quad[\mathrm{~mm}]$ blade pitch

$x \quad[\mathrm{~mm}]$ axial distance in cascade frame

$y \quad[\mathrm{~mm}]$ pitchwise distance in cascade frame

$\Delta \bar{C}_{p} \quad$ [1] steady surface pressure coefficient deviation from blade \#5

$\gamma \quad[\mathrm{dg}]$ blade stagger angle (from axial direction)

$\pi_{\mathrm{TB}} \quad$ [1] cascade pressure ratio, $\bar{P}_{2} / \bar{P}_{1}$

$\rho \quad\left[\mathrm{kg} / \mathrm{m}^{3}\right]$ air density

$\theta \quad[\mathrm{dg}]$ blade camber

$\xi \quad[\mathrm{mm}]$ airfoil chordwise distance

$\sigma_{\mathrm{M}} \quad[1 / \mathrm{s}]$ rate of sonic crossings

$\sigma_{\mathrm{px}} \quad[\mathrm{kPa}] \mathrm{RMS}$ of surface pressure

- $\quad$ average value

\section{REFERENCES}

Boldman, D. R., and Buggele, A. E. 1978. Wind Tunnel Tests of a Blade Subjected to Midchord Torsional Oscillations at High Subsonic Stall Flutter Conditions. NASA TM-78998.

Buffum, D. H., Capece, V. R., King, A. J., and El-Aini, Y. M. 1996. Oscillating Cascade Aerodynamics at Large Mean Incidence. ASME Paper 96-GT-339.

Chima, R. V. 1987. Explicit Multigrid Algorithm for Quasi-ThreeDimensional Viscous Flows in Turbomachinery. AIAA J. Propulsion and Power 3(5):397-405. 
Chima, R. V. 1995. A k- $\omega$ Turbulence Model for Quasi-ThreeDimensional Turbomachinery Flows. AIAA Paper 96-0248 NASA TM-107051.

Chima, R. V., McFarland, E. R., Wood, J. R., and Lepicovsky, J. 2000. On Flowfield Periodicity in the NASA Transonic Flutter Cascade, Part II-Numerical Study, ASME Paper 2000-GT-0573.

Lepicovsky, J., Chima, R. V., Jett, T. A., Bencic, T. J., and Weiland, K. E. 2000a. Investigation of Flow Separation in a Transonic-Fan Linear Cascade Using Visualization Methods, International Symposium on Flow Visualization, Paper 335.

Lepicovsky, J., McFarland, E. R., Chima, R. V., and Wood, J. R. 2000b. On Flowfield Periodicity in the NASA Transonic Flutter Cascade, Part I-Experimental Study, ASME Paper 2000-GT-0572.
Lepicovsky, J., McFarland, E. R., Chima, R. V, and Wood, J. R. 2001. On Flowfield Periodicity in the NASA Transonic Flutter Cascade, Journal of Turbomachinery 123:501-509.

Lepicovsky, J., McFarland, E. R., Capece, V. R., Jett, T. A., and Senyitko, R. G. 2002. Methodology of Blade Unsteady Pressure Measurement in the NASA Transonic Flutter Cascade, NASA/TM2002-211894.

McFarland, E. R. 1993. An Integral Equation Solution for Multistage Turbomachinery Design Calculations, ASME Paper 93-GT-41.

McFarland, E. R. 1994. Use of Preliminary Design Methods in the Analysis of Multi-Stage Turbomachinery, NASA CP 3282, Vol. 2.

Shaw, L. M., Boldman, D. R., Buggele, A. E., and Buffum, D. H. 1986. Unsteady Pressure Measurements on a Biconvex Airfoil in a Transonic Oscillating Cascade. Journal of Engineering for Gas Turbines and Power 108:53-59. 

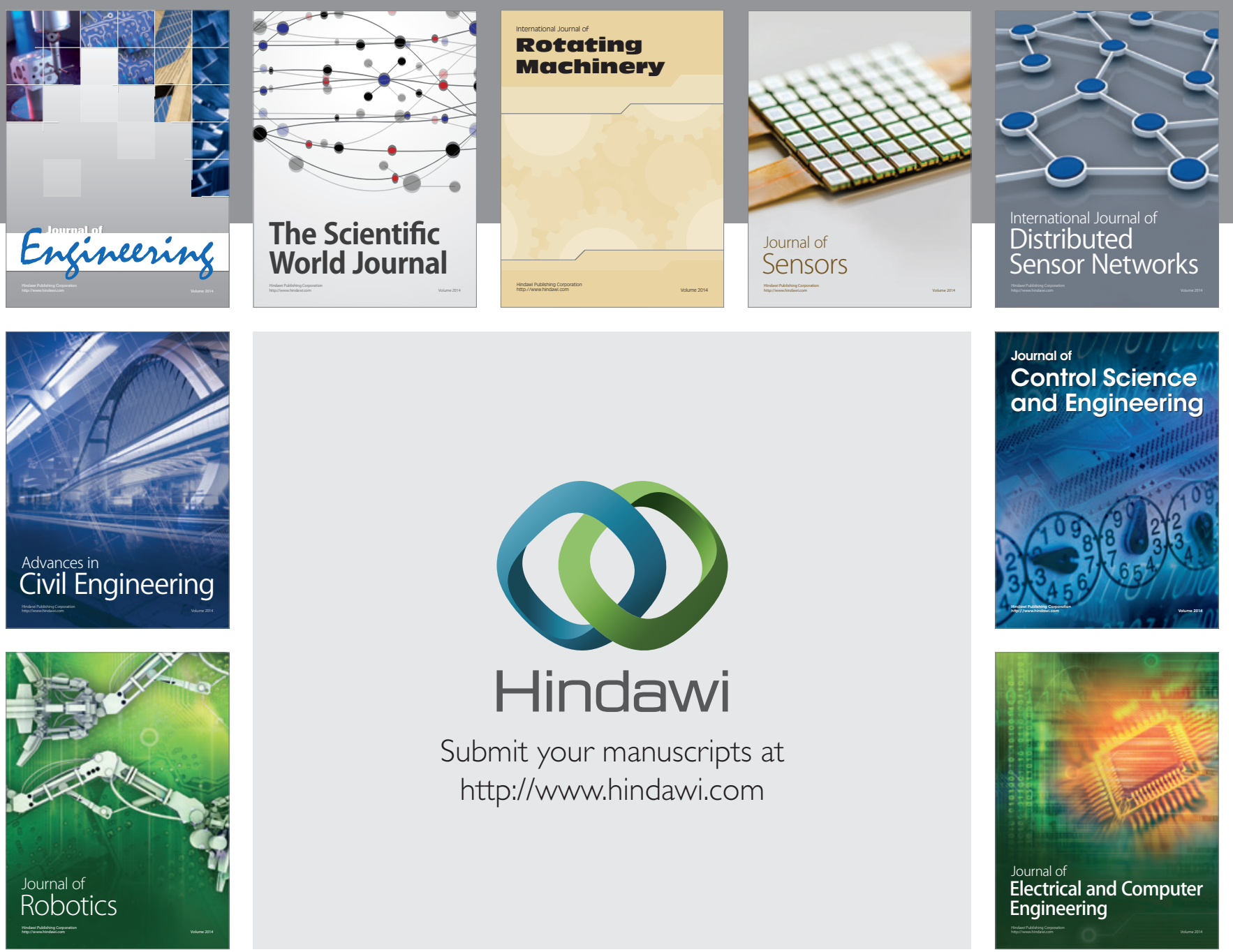

Submit your manuscripts at

http://www.hindawi.com
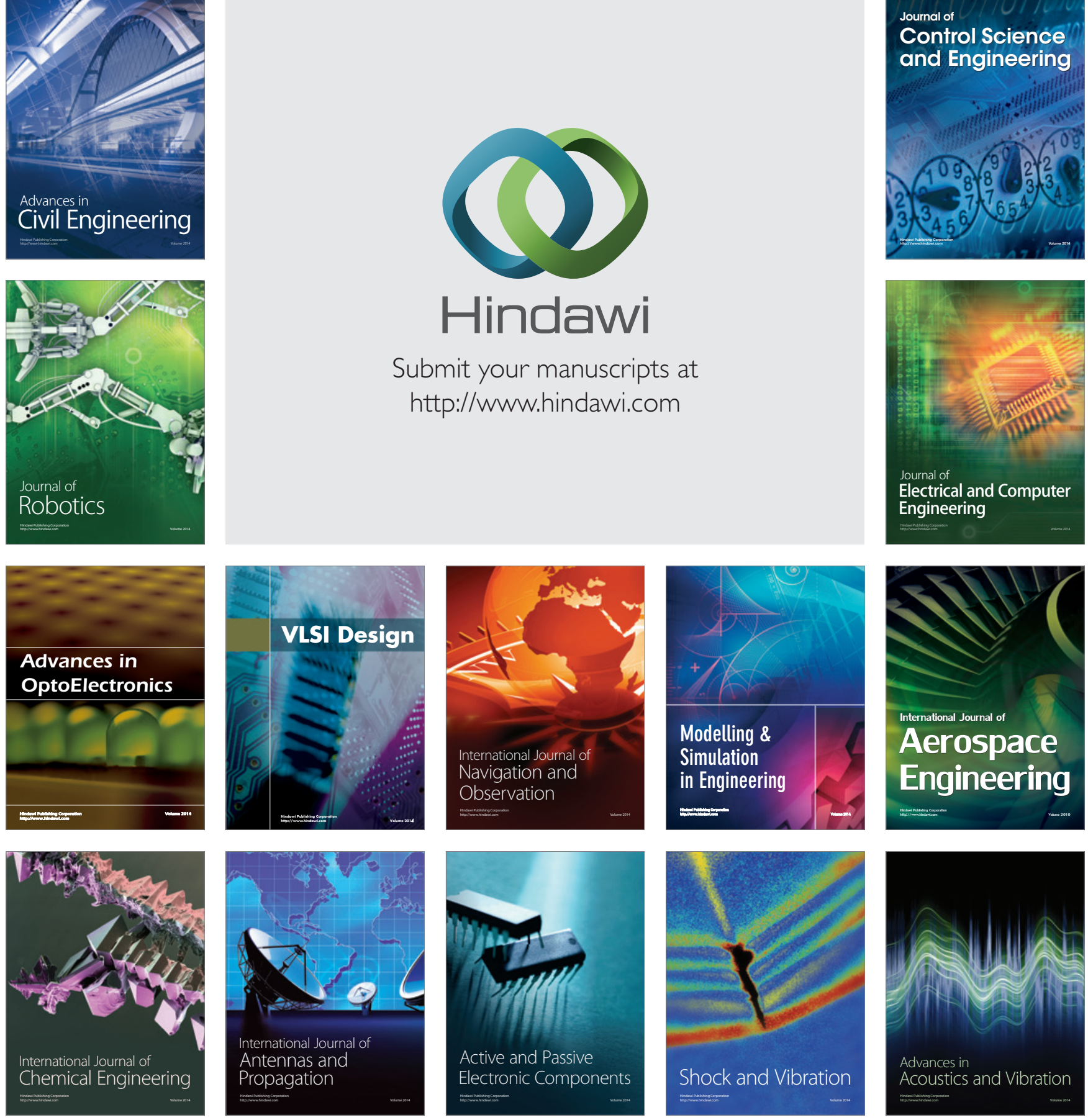